\title{
Fishing line assisted endoscopic placement of multiple plastic biliary stents for unresectable malignant hilar biliary obstruction: a retrospective study
}

\author{
Huahui Zhang ${ }^{1}$, Fengdong $\mathrm{Li}^{2}$, Jian Huang ${ }^{2}$, Chunyan $\mathrm{HuO}^{2^{*}}$ and Jin Huang ${ }^{2^{*}}$
}

\begin{abstract}
Background and aims: Stent migration is one of the most common complications during the placement of multiple plastic biliary stents (MPBS) under endoscopy. This study aims to evaluate the feasibility and efficiency of the fishing line assisted (FLA) method for preventing the complication.

Methods: Patients with unresectable malignant hilar biliary obstruction (MHBO) who undergone endoscopic placement of MPBS using the FLA or conventional method from May 2018 to April 2021 in our center were enrolled in the study. The endpoints of this study were the stent migration rate, technical success rates, adverse events rates, times of stent migration, and the procedure time.

Results: FLA group $(N=19)$ and conventional group $(N=22)$ had similar baseline characteristics of the patients. The technical success rates (100\% vs. $95.5 \%$; $P>0.05)$, ERCP-related adverse events rates (5.3\% vs. 4.5\%; $P>0.05)$, and the stent-related adverse events rates ( $0 \%$ vs. $4.5 \%$; $P>0.05$ ) were no significant differences between the FLA and conventional groups. MPBS inserted using the conventional method consumed more time (median, 33.9 min vs. 15.6 min; $P<0.05$ ) method and increased the times of stent migration (median, 3 times vs. 0 times; $P<0.05$ ) than using the FLA method. Even if no statistical difference was detected in the stent migration rate between groups, this rate was lower in the FLA group than the conventional group (0\% vs. 13.6\%; $P>0.05$ ).
\end{abstract}

Conclusions: FLA method is an effective technique for MPBS implantation to prevent stent migration during endoscopic retrograde cholangiography (ERCP). The method should be applied to patients with unresectable MHBO who need to place MPBS.

Keywords: Plastic biliary stent, Fishing line assisted method, Stent migration, Endoscopic retrograde cholangiography, Malignant hilar biliary obstruction

*Correspondence: 1849815361@qq.com; hj042153@hotmail.com 2 Department of Gastroenterology, The Affiliated Changzhou No.2 People's Hospital of Nanjing Medical University, No. 68, Gehu Middle Road, Wujin District, Changzhou City 213100, Jiangsu Province, China Full list of author information is available at the end of the article

\section{Background}

MHBO results from cholangiocarcinoma, hepatocellular carcinoma, gallbladder cancer, and other cancer metastasis to the regional lymph nodes [1,2]. Patients with MHBO have a poor quality of life owing to pruritus, loss of appetite, and general debility caused by jaundice $[3,4]$. Biliary drainage is widely used to relieve those symptoms in patients with $\mathrm{MHBO}$ and improve the quality of life 
of patients. The placement of stents during ERCP in the obstruction region is an effective palliation method, this program is often done by the experienced endoscopist $[5,6]$. Plastic biliary stent (PBS) placement has been firstly reported in the early 1980s [7], PBS is more economical and the effect is similar [8], compared with metal stents. Patients with unresectable MHBO usually need to insert MPBS during ERCP [9-11]. However, the first stent upward migration usually occurred during the second stent inserted due to the friction between the two stents. Endoscopists had to spend a lot of time adjusting the position of the stents. Based on the previous literature data, many methods were reported to prevent stent upward and downward migration after stents implantation rather than the process of stents implantation [1214]. To fill the gap in this problem, we invented a novel technology known as the FLA method. In the study, we evaluate the safety and feasibility of the method for MPBS placement.

\section{Methods}

\section{Patients}

In total, consecutive 41 patients from May 2018 to April 2021 in our center meet our inclusion criteria. The inclusion criteria for the study were as follows: (1) patients who had unresectable MHBO and (2) patients who performed endoscopic biliary drainage using MPBS by the FLA or conventional method. (3) All clinical, laboratory, and imaging data of the patients can be obtained from our medical record system. The exclusion criteria for this research were as follows : (1) patients had a history of both biliary stent placement and percutaneous transhepatic biliary drainage (PTBD). (2) Two stents were both inserted into the right or left hepatic duct and (3) clinical data of patients is incomplete. The location of obstruction was based on examination of computer tomography $(\mathrm{CT})$, magnetic resonance imaging (MRI), or ERCP. Malignant stenosis involving the hilum is classified by using the Bismuth-Corlette classification system. Bismuth type I stenosis involves the proximal common hepatic duct and spares the confluence between the left and right ductal systems. Type II stenosis involves the confluence and spares the segmental hepatic ducts. Type IIIa and IIIb stenosis involve either the right or left segmental hepatic duct, respectively, and type IV stenosis involves the confluence and both the right and left segmental hepatic ducts. All patients had no contradiction for endoscopic biliary drainage and gave written informed consent for the ERCP procedure.

\section{Stents}

Straight stents with a diameter of 7-Fr or 8.5 -Fr were used in our study. We created two side holes of the distal end of the first plastic stent using a scalpel on a sterile operating table which was to make sure the fishing line going through (Fig. 1).

\section{FLA method for stent implantation}

All patients underwent stent implantation under anesthesia and sedation in our endoscopic operating room. ERCP was performed in all patients with a gastroduodenal endoscope by two senior experienced endoscopists before the stent implantation. After successful bile duct intubation, the most severe part of the bile duct dilatation in right or left hepatic duct was inserted a guide wire and the structure was dilated repeatedly by ballon under the X-ray fluoroscopy guidance, respectively. Before the implantation of the stent, a sphincterotomy was performed to facilitate the implantation of stents. The stent placement inside the bile duct was as follows: (1) After being treated with liquid paraffin, a 3-m long fishing line was going through the side hole at the distal end of the first PBS (Fig. 1). (2) The first PBS was inserted into the right or left hepatic duct along the guidewire through the endoscopic channel using a stent delivery catheter. And the double tails of the fishing line were left outside of the endoscopic channel for hand control (Fig. 2). (3) The first PBS was pulled by the fishing line and kept its desired location under endoscopic and fluoroscopic surveillance when the second PBS was inserted into the other side hepatic duct. Besides, the fishing line always maintained tension to prevent the first PBS upward migration during the process of the second PBS implantation (Fig. 3). (4)

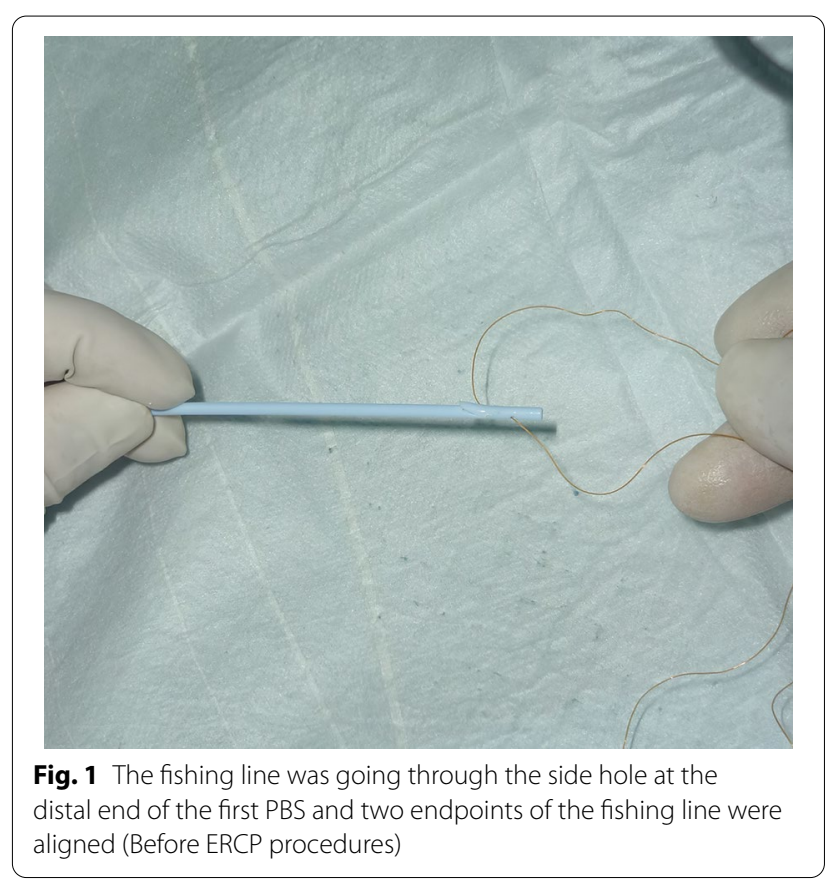




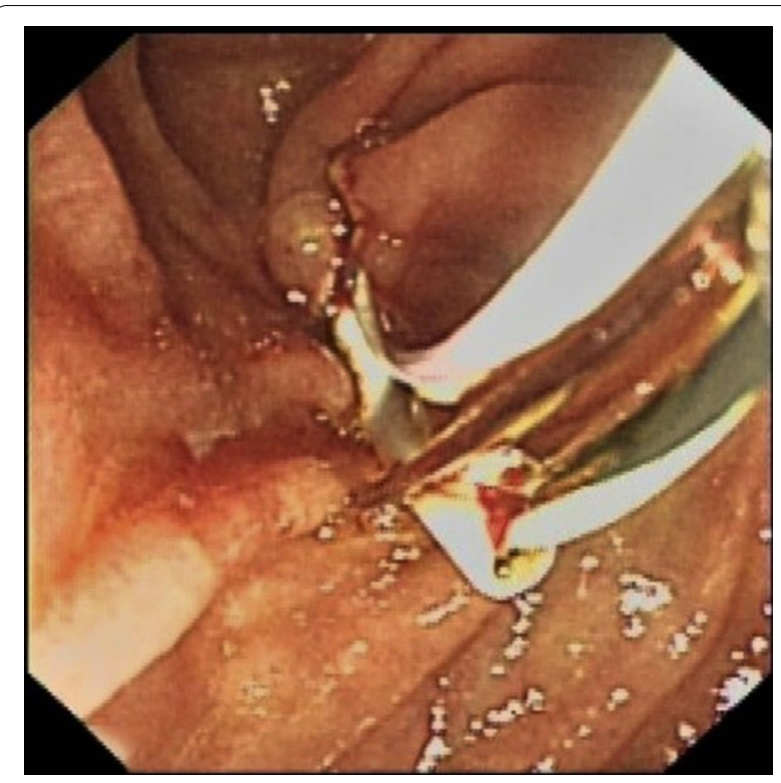

Fig. 2 The first PBS was inserted into the right or left hepatic duct through the endoscopic channel with the assistance of a stent delivery catheter, meanwhile, the fishing line at the distal end of the first PBS could be observed under endoscopy

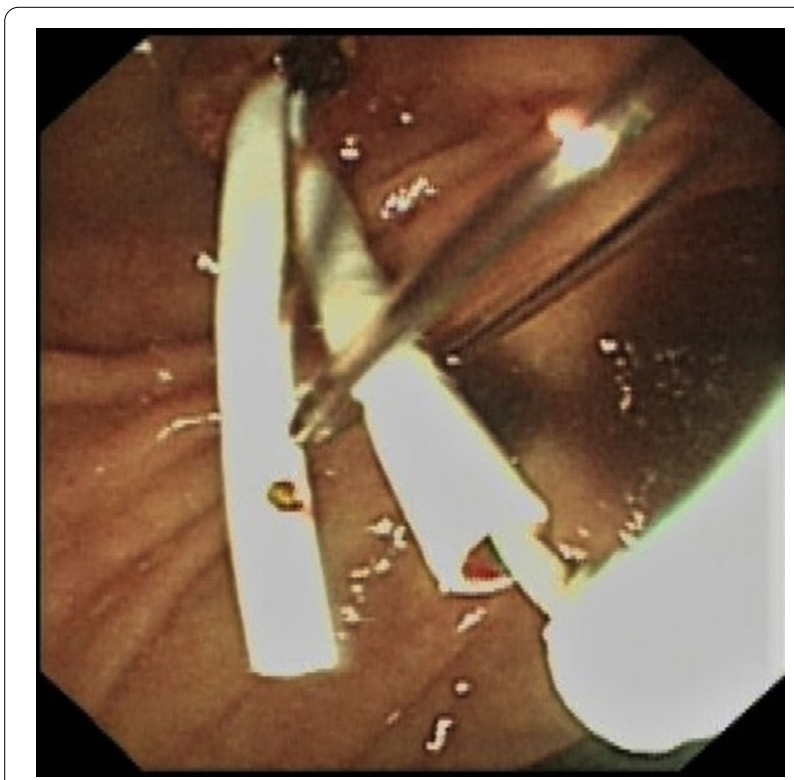

Fig. 3 The second PBS was placed in the other side hepatic duct, meanwhile, the fishing line maintained tension to prevent the first PBS upward migration
After the second stent was placed successfully the clever knife was used as a stent delivery catheter to withstand the distal end of the first PBS, then either endpoint of the fishing line was grabbed at the entrance to the endoscopic channel and the fishing line was pulled out of side hole at the distal end of the first PBS through the endoscopic channel, at last, the guidewire was withdrawn from the stents (Additional file 1: Video 1) (Fig. 4).

\section{Conventional method for stent implantation}

After successful bile duct cannulation, guidewires were led to the left hilar duct and/or the right hilar duct under the surveillance of fluoroscopy. Similar to the FLA method the structure was also dilated by ballon and a sphincterotomy was performed. At last, the first and second stents were inserted into the bile duct along guidewires using a stent delivery catheter. The appropriate length of prostheses was selected according to the location of strictures. At the 3 months after procedures, ERCP was performed for stent exchange or removal.

\section{Outcomes}

The stent migration rate, technical success rates, times of stent migration, adverse events, and procedures time between two groups were evaluated in this study. Proximal migration was defined as when stent was observed in the duct on fluoroscopy and the distal end of the stent was not observed under endoscopy. Distal migration was defined as when stent located below the original position or was not observed under either endoscopy or fluoroscopy. Technical success was defined as the placement of all stents over the stricture location, the distal end of the stent in the intestinal cavity is almost flush and constraint medium

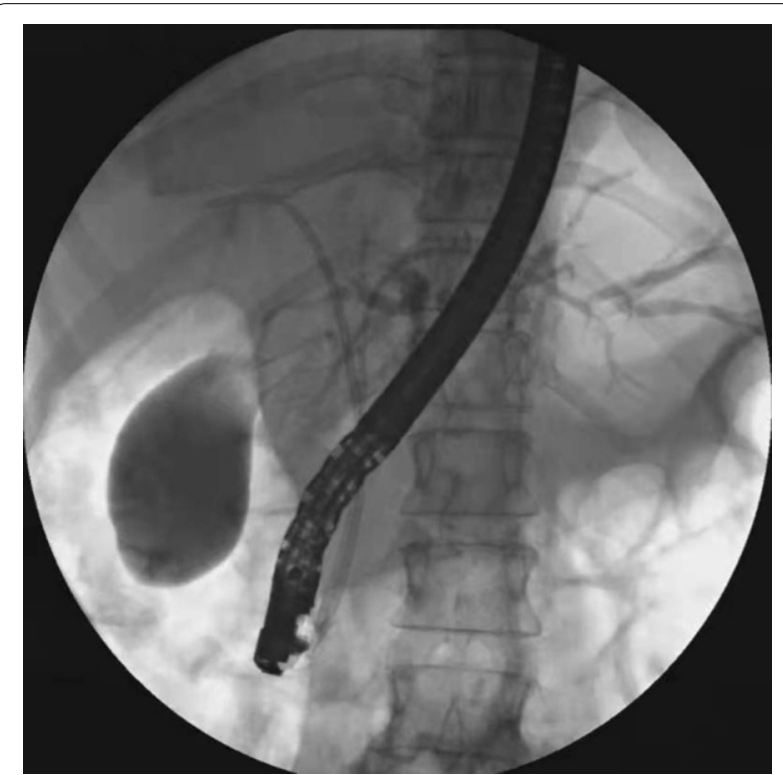

Fig. 4 Two PBS were successfully implanted in the left and right hepatic duct 
Table 1 Characteristics of the patients

\begin{tabular}{|c|c|c|c|}
\hline & $\begin{array}{l}\text { FLA group } \\
(\mathrm{N}=19)\end{array}$ & $\begin{array}{l}\text { Conventional group } \\
(\mathrm{N}=22)\end{array}$ & $P$ value \\
\hline Sex (Male/Female) & $11 / 8$ & $13 / 9$ & 0.94 \\
\hline Age (median, years) (range) & $68(52-82)$ & $70(56-88)$ & 0.21 \\
\hline \multicolumn{4}{|l|}{ Clinical symptoms, n (\%) } \\
\hline Jaundice & $11(57.9)$ & $12(54.5)$ & 0.83 \\
\hline Abdominal pain & $10(52.6)$ & $9(40.9)$ & 0.45 \\
\hline Weight loss & $8(42.1)$ & $11(50)$ & 0.61 \\
\hline Anorexia & $7(36.8)$ & $6(27.3)$ & 0.51 \\
\hline Fatigue & $3(15.8)$ & $5(22.7)$ & 0.87 \\
\hline \multicolumn{4}{|l|}{ Laboratory data } \\
\hline T-Bil (median, mg/dL) (range) & $6.3(2.8-13.1)$ & $5.8(3.6-17.5)$ & 0.65 \\
\hline Albumin (mean $\pm S D, g / d l)$ & $3.3 \pm 0.72$ & $3.5 \pm 0.60$ & 0.59 \\
\hline ALT (median, IU/L) (range) & $56.8(10.5-1319.0)$ & $60.4(12.9-789.8)$ & 0.43 \\
\hline CA19-9 (median, U/mL) (range) & $110.2(12.6-336.7)$ & $97.7(17.6-446.7)$ & 0.11 \\
\hline Causes of strictures, n (\%) & & & 0.97 \\
\hline Hilar cholangiocarcinoma & $8(42.1)$ & $10(45.5)$ & \\
\hline Gallbladder carcinoma & $4(21.1)$ & $5(22.7)$ & \\
\hline Hepatocellular carcinoma & $3(15.8)$ & $4(18.2)$ & \\
\hline Metastatic cancers & $4(21.1)$ & $3(13.6)$ & \\
\hline Bismuth classification (\%) & & & 0.88 \\
\hline$\|$ & $2(10.5)$ & $1(4.5)$ & \\
\hline III & $4(21.1)$ & $5(22.7)$ & \\
\hline IV & $13(68.4)$ & $16(72.7)$ & \\
\hline TNM stage, n (\%) & & & 0.86 \\
\hline$\|$ & $2(10.5)$ & $2(9.1)$ & \\
\hline III & $3(15.8)$ & $2(9.1)$ & \\
\hline IV & $14(73.7)$ & $18(81.8)$ & \\
\hline \multicolumn{4}{|l|}{ Basic diseases, n (\%) } \\
\hline Hypertension & $5(26.3)$ & $6(27.3)$ & 0.95 \\
\hline Diabetes & $2(10.5)$ & $2(9.1)$ & 0.88 \\
\hline Cardiovascular disease & $3(15.8)$ & $3(13.6)$ & 0.85 \\
\hline Kidney disease & $1(5.3)$ & $3(13.6)$ & 0.71 \\
\hline Stent size & & & 0.76 \\
\hline $7 \mathrm{Fr}+7 \mathrm{Fr}$ & $9(47.4)$ & $13(59.1)$ & \\
\hline $8.5 \mathrm{Fr}+8.5 \mathrm{Fr}$ & $7(36.8)$ & $6(27.3)$ & \\
\hline $7 \mathrm{Fr}+8.5 \mathrm{Fr}$ & $3(15.8)$ & $3(13.6)$ & \\
\hline
\end{tabular}

or bile juice can flow the stent. The procedure time was recorded from the preparation of implantation of the first stent to the second stent was inserted completely. The times of stent migration were defined as the number of times the first stent migrates into the bile duct or duodenal intestinal cavity during ERCP. Cholangitis, pancreatitis, bleeding, and perforation were recorded as ERCP-related adverse events. Stentrelated adverse events included biliary bleeding and perforation.

\section{Statistics}

Continuous data conforming to the normal distribution are represented as mean \pm standard deviation (SD), or continuous data are represented as median (range). Categorical variables were compared with the Chi-square test or Fisher's exact test. Continuous variables were compared with by Student's or non-parametric Wilcoxon rank-sum test. A $P<0.05$ was considered to be statistically significant. All data processing and analysis were used by IBM SPSS. 
Table 2 Outcomes

\begin{tabular}{|c|c|c|c|}
\hline & FLA group $(N=19)$ & $\begin{array}{l}\text { Conventional group } \\
(\mathrm{N}=22)\end{array}$ & $P$ value \\
\hline The stent migration rate, $\mathrm{n}(\%)$ & $0(0)$ & $3(13.6)$ & 0.10 \\
\hline Technical success rates, n (\%) & $19(100)$ & $21(95.5)$ & 0.35 \\
\hline Procedures time, (median, min) (range) & $15.6(12.6-23.3)$ & $33.9(21.8-38.7)$ & 0.00 \\
\hline \multicolumn{4}{|l|}{ Adverse events, n (\%) } \\
\hline ERCP-related & $1(5.3)$ & $1(4.5)$ & 0.92 \\
\hline Pancreatitis & $1(5.3)$ & $1(4.5)$ & 0.92 \\
\hline Others & $0(0)$ & $0(0)$ & - \\
\hline Stent-related & $0(0)$ & $1(4.5)$ & 0.35 \\
\hline Biliary perforation & $0(0)$ & $0(0)$ & - \\
\hline Biliary bleeding & $0(0)$ & $1(4.5)$ & 0.35 \\
\hline Times of stent migration,(median, times) (range) & $0(0-2)$ & $3(1-5)$ & 0.00 \\
\hline
\end{tabular}

\section{Results}

\section{Patients information}

There were 41 patients were enrolled in our research. 19 patients in the FLA group and 22 patients in the conventional group were analyzed in our study. Two groups had similar baseline characteristics (Table 1).

\section{Technical success rates, the stent migration rate,} and times of stent migration

All patients were successfully inserted MPBS in the FLA group. The technical success rates were $95.5 \%$ (21/22) in the conventional group. The technical success rates were no difference between the two groups. One patient (4.5\%) in the conventional group had failed MPBS inserted owing to longer procedure time, and the patient was performed MPBS placement successfully using the FLA method. A total of 3 patients (13.6\%) experienced stent migration in the conventional group, proximal migration in two cases (9.1\%) and distal migration in one case (4.5\%). None of the patients experienced stent migration in the FLA group. All migrated stents were retrieved under endoscopy. There was no significant difference in the stent migration rate between groups (0\% VS 13.6\%; $P>0.05)$. The median (range) times of stent migration were $0(0-2)$ and $3(1-5)$ times in the FLA and conventional groups, respectively. The times of stent migration between the FLA and conventional groups were statistically significant (median, 0 times vs. 3 times; $P<0.05$ ) (Table 2).

\section{Adverse events and procedures time}

One patient $(5.3 \%)$ in the FLA group and one patient (4.5\%) in the conventional group experienced mild pancreatitis after the procedure and recovered shortly after treatment. None patients developed biliary bleeding or perforation in the FLA group. One patient (4.5\%) experienced biliary bleeding in the conventional group. The median time of procedures was 33.9 min ranged from 21.8 to $38.7 \mathrm{~min}$ in the conventional group. The procedures time ranged from 12.6 to $23.3 \mathrm{~min}$ with a median time of $15.6 \mathrm{~min}$. The time of procedures in the conventional group was significantly longer than the FLA group (median, 33.9 min vs. $15.6 \mathrm{~min} ; P<0.05$ ) (Table 2 ).

\section{Discussion}

ERCP and PTBD are the most common technology for biliary drainage in $\mathrm{MHBO}$. However, PTBD drains bile out of the body which may disrupt the patient's digestive function. A study in the United States showed that patients performed by ERCP experienced fewer adverse events than patients who performed PTBD [15]. A recent randomized clinical trial study had to terminate because of the high mortality rate in the PTBD group. Their existing data also shows that ERCP was safer than PTBD [16]. Therefore, ERCP usually was the first choice for biliary drainage in MHBO. However, the first stent tends to migrate to the bile duct, and the second stent incline to migrate to the duodenum during ERCP. We created a novel method named the FLA method to solve the problem. Our study indicates that the FLA method can effectively assist the placement of the bile duct stent, and reduce the procedure time (median, $15.6 \mathrm{~min}$ vs. $33.9 \mathrm{~min} ; P<0.05$ ) and the times of stent migration (median, 0 times vs. 3 times; $P<0.05$ ) compared with the conventional method.

Friction between the bile duct and stents can't be eliminated, especially in the case of bile duct stricture. On one hand, stents can stay close together due to friction between stents, on the other hand, stents were easy to migrate during stents inserted. Endoscopists need a lot of time to adjust the location of stents to make sure the biliary stents were located in the best position. The 
prolonged operation may increase the chance of cardiovascular and cerebrovascular complications. Repeatedly adjusting the position of the stent in the bile duct may result in bile duct damage. In the conventional group, one patient experienced biliary bleeding. It may be due to the long-time friction between the stent and bile duct.

A Japanese study reported a modified PBS for hilar stenosis [11]. A Nylon thread attached to a hole punched into the distal end of the stent for removal. In this study, the stent was implanted above the papilla of the duodenum, which was called "inside stent" $[11,17]$. However, there was no obvious evidence that the inside stent could prevent the first stent migration during the second stent implantation. Besides, migration or dislocation of stents was still a problem for inside stent [18]. Furthermore, a randomized trial study reported that the stent was difficult to remove in the inside stent group [19]. The duodenal papilla and bile duct may be damaged during the process of retrieving the stents. Single pigtail stent may have prevented the stent upward migration, however, single pigtail stent was expensive, and it may be easy to migrate to the duodenum owing to the pigtail structure. Besides, single pigtail stent was widely used to implant the pancreatic duct rather than the bile duct. We developed a technique named the "FLA method" in the endoscopic placement of MPBS. In this study, compared with conventional techniques, the FLA method for MPBS implantation, not only minimizes the consumption of time but also reduces the rate of stent migration. The overall stent migration rate was $7.3 \%(3 / 41)$ in the current study. The incidence of stent migration had been reported to range from 5 to $10 \%$ in biliary stenting patients $[14,20,21]$, which was similar to our results. The stent migration rate in the FLA group was lower than that in the conventional group, but it was not statistically significant ( $0 \%$ VS $13.6 \% ; P>0.05)$. The reason may be that the sample of our study was too small. The merit of this technique is below: (1) the first stent was pulled and fixed by the fishing line. At the time of subsequent stents insertion, the fishing line could work as the anchor by grabbing its endpoints to avoid the previous stents migrating to the proximal bile duct. (2) Guidewires were left in stents over the process to adjust their position expediently. If the first stent migrated down to the duodenum, we inserted a knife along the guidewire to push the stent to the desired position under the monitoring of $\mathrm{X}$-ray with fishing line release. (3) While the fishing line was pulled out of the side hole in the first stent, the knife was inserted along the guidewire and withstand the endpoint of the stent to maintain its location.

There are some limitations to this study. First, the sample size was small a large-scale multicenter study is required to meet the statistical calculation. A second limitation is the lack of blinding of the physician to the procedure.

In conclusion, the FLA method is an effective technique for multiple plastic biliary stents implantations to prevent stent dislocation. It improves the accuracy of the stent's location and reduces the need for time-consuming.

\section{Abbreviations}

MPBS: Multiple plastic biliary stents; FLA: Fishing line assisted; MHBO: Malignant hilar biliary obstruction; ERCP: Endoscopic retrograde cholangiography; PBS: Plastic biliary stent; PTBD: Percutaneous transhepatic biliary drainage; CT: Computer tomography; MRI: Magnetic resonance imaging; SD: Standard deviation; T-Bil: Total bilirubin; ALT: Alanine aminotransferase.

\section{Supplementary Information}

The online version contains supplementary material available at https://doi. org/10.1186/s12876-021-02014-x.

Additional file 1: Video 1. It shows the process of retrieving the fishing line from the first PBS. In brief, either endpoint of the fishing line was grabbed and pulled at the entrance to the endoscopic channel to remove the fishing line from the side hole of the first PBS.

\section{Acknowledgements}

We thank the cooperation and assistance provided by all medical staff of the department of Gastroenterology, The Affiliated Changzhou No. 2 People's Hospital of Nanjing Medical University.

\section{Authors' contributions}

J.H. \& C.H. contributed to the study concept and design. H.Z. contributed to the writing and drafting of this manuscript. Data collection and analysis were provided by F.L. \& J.H. All authors read and approved the final manuscript.

\section{Funding}

Not applicable.

\section{Availability of data and materials}

The datasets used or analyzed during the current study are available from the corresponding author on reasonable request.

\section{Declarations}

\section{Ethics approval and consent to participate}

All procedures were performed in accordance with the guidelines of the National Institutes of Health of China and with the Helsinki Declaration of 1964 and later versions. This study was approved by the Ethics Committee of the Affiliated Changzhou No.2 people's Hospital of Nanjing Medical University. Informed consent for this study was waived by the Ethics Committee of the Affiliated Changzhou No.2 people's Hospital of Nanjing Medical University because the study was conducted retrospectively.

\section{Consent for publication}

Not applicable.

\section{Competing interests}

All authors have no competing interests.

\section{Author details}

${ }^{1}$ Graduate School of Dalian Medical University, Dalian, China. ${ }^{2}$ Department of Gastroenterology, The Affiliated Changzhou No.2 People's Hospital of Nanjing Medical University, No. 68, Gehu Middle Road, Wujin District, Changzhou City 213100, Jiangsu Province, China. 
Received: 15 July 2021 Accepted: 1 November 2021

Published online: 19 November 2021

\section{References}

1. Leng J-J, Zhang N, Dong J-H. Percutaneous transhepatic and endoscopic biliary drainage for malignant biliary tract obstruction: a meta-analysis. World J Surg Oncol. 2014;12(1):272.

2. Xia MX, Cai XB, Pan YL, Wu J, Gao DJ, Ye X, Wang TT, Hu B. Optimal stent placement strategy for malignant hilar biliary obstruction: a large multicenter parallel study. Gastrointest Endosc. 2020;91(5):1117-1128 e1119.

3. Lee $\mathrm{TH}$, Moon JH, Park SH. Biliary stenting for hilar malignant biliary obstruction. Dig Endosc. 2020;32(2):275-86.

4. Kapoor BS, Mauri G, Lorenz JM. Management of biliary strictures: state-ofthe-art review. Radiology. 2018;289(3):590-603.

5. Deprez PH, Moreels TG, Aouattah T, Piessevaux H, Pérez-Cuadrado-Robles E. A new 12-French plastic stent for unresectable distal malignant biliary obstruction. Endoscopy. 2020;52(6):474-82.

6. Yuan XL, Ye LS, Liu Q, Wu CC, Liu W, Zeng XH, Zhang YH, Guo LJ, Zhang $Y Y, L i Y$, et al. Risk factors for distal migration of biliary plastic stents and related duodenal injury. Surg Endosc. 2020;34(4):1722-8.

7. Paik WH, Woo SM, Chun JW, Song BJ, Lee WJ, Ahn DW, Lee YS, Choi YH, Ryu JK. Kim YT et al: Efficacy of an internal anchoring plastic stent to prevent migration of a fully covered metal stent in malignant distal biliary strictures: a randomized controlled study. Endoscopy. 2021:53(6):578-85.

8. Song TJ, Lee JH, Lee SS, Jang JW, Kim JW, Ok TJ, Oh DW, Park DH, Seo DW, Lee SK, et al. Metal versus plastic stents for drainage of malignant biliary obstruction before primary surgical resection. Gastrointest Endosc. 2016;84(5):814-21.

9. Iwasaki A, Kubota K, Kurita Y, Hasegawa S, Fujita Y, Kagawa K, Kato S, Sekino Y, Hosono K, Nakajima A. The placement of multiple plastic stents still has important roles in candidates for chemotherapy for unresectable perihilar cholangiocarcinoma. J Hepatobiliary Pancreat Sci. 2020:27(10):700-11.

10. Tomoda T, Kato H, Kawamoto H, Muro S, Akimoto Y, Uchida D, Matsumoto K, Horiguchi S, Tsutsumi K, Okada H. Usefulness of a newly designed plastic stent for endoscopic re-intervention in patients with malignant hilar biliary obstruction. Endoscopy. 2017;49(11):1087-91.

11. Kaneko T, Sugimori K, Shimizu Y, Miwa H, Kameta E, Koh R, Numata K, Tanaka K, Maeda S. Efficacy of plastic stent placement inside bile ducts for the treatment of unresectable malignant hilar obstruction (with videos). J Hepatobiliary Pancreat Sci. 2014;21(5):349-55.
12. Paik WH, Woo SM, Chun JW, Song BJ, Lee WJ, Ahn D-W, Lee YS, Choi YH, Ryu JK, Kim Y-T, et al. Efficacy of an internal anchoring plastic stent to prevent migration of a fully covered metal stent in malignant distal biliary strictures: a randomized controlled study. Endoscopy. 2021;53(6):578-85.

13. Bordaçahar B, Perdigao F, Leblanc S, Barret M, Duchmann J-C, Guillaumot MA, Chaussade S, Scatton O, Prat F. Clinical efficacy of anti-migration features in fully covered metallic stents for anastomotic biliary strictures after liver transplantation: comparison of conventional and anti-migration stents. Gastrointestinal endoscopy. 2018:88(4):655-64.

14. Cheon YK, Oh H-C, Cho YD, Lee TY, Shim CS. New 10F soft and pliable polyurethane stents decrease the migration rate compared with conventional 10F polyethylene stents in hilar biliary obstruction: results of a pilot study. Gastrointestinal endoscopy. 2012;75(4):790-7.

15. Inamdar S, Slattery E, Bhalla R, Sejpal DV, Trindade AJ. Comparison of adverse events for endoscopic vs percutaneous biliary drainage in the treatment of malignant biliary tract obstruction in an inpatient national cohort. JAMA Oncol. 2016;2(1):112-7.

16. Coelen RJS, Roos E, Wiggers JK, Besselink MG, Buis Cl, Busch ORC, Dejong $\mathrm{CHC}$, van Delden OM, van Eijck CHJ, Fockens P, et al. Endoscopic versus percutaneous biliary drainage in patients with resectable perihilar cholangiocarcinoma: a multicentre, randomised controlled trial. Lancet Gastroenterol Hepatol. 2018;3(10):681-90.

17. Kuwatani M, Kawakubo K, Sakamoto N. Possible reasons for the regrettable results of patency of an inside stent in endoscopic transpapillary biliary stenting. Dig Endosc. 2021. https://doi.org/10.1111/den.14006.

18. Matsushita M, Hajiro K, Takakuwa H, Nishio A. Are biliary stents placed above the sphincter of oddi really ineffective? Gastrointestinal Endoscopy. 2000;51(1):116-7.

19. Pedersen FM, Lassen AT, Schaffalitzky de Muckadell OB. Randomized trial of stent placed above and across the sphincter of Oddi in malignant bile duct obstruction. Gastrointestinal Endoscopy. 1998;48(6):574-9.

20. Arhan M, Odemiş B, Parlak E, Ertuğrul I, Başar O. Migration of biliary plastic stents: experience of a tertiary center. Surg Endosc. 2009;23(4):769-75.

21. Taj MA, Ghazanfar S, Qureshi S, Zubair M, Niaz SK, Quraishy MS. Plastic stent migration in ERCP; a tertiary care experience. J Pak Med Assoc. 2019:69(8):1099-102.

\section{Publisher's Note}

Springer Nature remains neutral with regard to jurisdictional claims in published maps and institutional affiliations.
Ready to submit your research? Choose BMC and benefit from:

- fast, convenient online submission

- thorough peer review by experienced researchers in your field

- rapid publication on acceptance

- support for research data, including large and complex data types

- gold Open Access which fosters wider collaboration and increased citations

- maximum visibility for your research: over $100 \mathrm{M}$ website views per year

At $\mathrm{BMC}$, research is always in progress.

Learn more biomedcentral.com/submissions 